\title{
Tail suspension delays ectopic ossification in proteoglycan-induced ankylosing spondylitis in mice via miR-103/DKK1
}

\author{
ZHENZHEN ZHANG $^{1-3 *}$, JING ZENG $^{1 *}$, YANG LI $^{1}$, QING LIAO $^{1}$, \\ DONGDONG HUANG ${ }^{1}$, YUCONG ZOU ${ }^{1}$ and GANG LIU ${ }^{1,2}$ \\ ${ }^{1}$ Department of Rehabilitation Medicine, The Third Affiliated Hospital of Southern Medical University, Guangzhou,
Guangdong 510000; ${ }^{2}$ Department of Rehabilitation Medicine, Nanfang Hospital, Southern Medical University,
Guangzhou, Guangdong 510515; ${ }^{3}$ Department of Rehabilitation, Hankou Hospital, Wuhan, Hubei 430015, P.R. China
}

Received October 14, 2020; Accepted June 15, 2021

DOI: $10.3892 /$ etm.2021.10397

\begin{abstract}
Ankylosing spondylitis (AS), characterized by inflammatory lesions and osteophyte formation, is a common immune rheumatic disease affecting the sacroiliac and axial joints. A high-intensity mechanical load is known to accelerate the heterotopic ossification associated with enthesitis in AS. Thus, the present study explored whether decreased mechanical load could delay the heterotopic ossification in AS. First, 24-week-old female BALB/c mice were induced with proteoglycan (PG) to establish an AS model. The AS-induced pathological and bone morphological changes of the sacroiliac joint were confirmed by hematoxylin and eosin staining and microCT analysis, respectively. Subsequently, the mice were treated with interventions of different mechanical loads. Using reverse transcription-quantitative PCR, it was revealed that expression levels of the osteogenesis-related genes bone morphogenetic protein-2, runt-related transcription factor 2 and osteocalcin were significantly reduced in sacroiliac bone tissue after intervention with a reduced mechanical load. The level of mechanosensory microRNA (miR)-103 increased in response to reduced mechanical loads. Consistently, in groups with reduced mechanical load, proteins with mechanical functions, including $\rho$-associated coiled-coil-containing protein kinase 1 (ROCK1), phosphorylated (p)-Erk1/2 and $\beta$-catenin, were reduced compared with the PG control. A dual-luciferase assay verified that miR-103 binds to the 3'-untranslated region end of Rockl mRNA, thus negatively regulating the activity of Rockl
\end{abstract}

Correspondence to: Professor Yucong Zou or Professor Gang Liu, Department of Rehabilitation Medicine, The Third Affiliated Hospital of Southern Medical University, 183 Zhong Shan Road West, Guangzhou, Guangdong 510000, P.R. China

E-mail: zyc0118@smu.edu.cn

E-mail:1g2781@smu.edu.cn

${ }^{*}$ Contributed equally

Key words: ankylosing spondylitis, microRNA-103, heterotopic ossification, mechanical load, Wnt $/ \beta$-catenin signaling pathway and affecting pathological ossification during AS. However, immunohistochemical staining indicated that the expression of dickkopf Wnt signaling pathway inhibitor 1, an inhibitor of the Wnt/ $\beta$-catenin pathway, was increased in sacroiliac tissues. The results indicated that tail suspension decreased the mechanical load, thus reducing the bone formation in AS mice. Furthermore, tail suspension could inhibit the activation of mechanical kinase ROCK1 and p-Erk1/2 in the MAPK signaling pathway by upregulating miR-103, thereby inhibiting the classical osteogenesis-related Wnt/ $\beta$-catenin pathway in AS. In summary, the present study uncovered the ameliorative effect of suspension on AS and its therapeutic potential for AS.

\section{Introduction}

Ankylosing spondylitis (AS) is a typical chronic autoimmune disease characterized by sacroiliac and spinal arthritis (1). New bone formation at the sacroiliac joint and spine are diagnostic features of AS (2). In addition to ectopic bone formation, chronic inflammation and bone erosion are the dominant pathophysiological manifestations of AS $(3,4)$. In AS, immune inflammation has been demonstrated to stimulate new bone formation at the attachment site, causing joint stiffness and mobility problems (4). The heterotopic ossification of various attachment points is the leading cause of disability in patients with AS (5). Excessive axial myofascial stress under overload conditions increases pain and the occurrence of joint movement disorders (6). Thus, an increased mechanical load may be a significant cause of ectopic new bone formation in AS. Previous studies have shown that mechanical stress is a major driving factor of ectopic osteogenic proliferation via the activation of the $\rho / \rho$-associated coiled-coil-containing protein kinase (ROCK) pathway (7) and the phosphorylation of the Erk1/2/MAPK signaling pathway (8). Biomechanical factors also play an notable role in the occurrence and development of AS, especially when the joints are overworked (9). When articular bone tissues are subjected to excessive biomechanical stress, heterotopic ossification of the cartilage and ligaments surrounding these tissues can be accelerated (4). Indeed, inflammation-induced ectopic bone formation requires the activation of the classical $\mathrm{Wnt} / \beta$-catenin pathway, which may be positively associated with heterotopic ossification. (10). 
Wnt/ $\beta$-catenin signaling is increased in patients with AS (11). When the biomechanical load is increased, the $\rho /$ ROCK pathway can also play a notable role in activating the Erk1/2 MAPK signaling pathway, stimulating heterotopic ossification (12).

Treatments for AS include not only drugs, but also non-pharmacological therapy. Because mechanical load stimulation plays an important role in disease progression, exercise therapy allows for training under reduced mechanical load, which may slow the progression of AS (13). A previous study reported that therapeutic exercise, such as spa exercise, can relieve AS symptoms in adults (13). Suspension also appears to be a promising modality; this method has been regularly applied to mechanical load reduction experiments $(14,15)$. In recent years, tail suspension to the point of no load-bearing has become popular as a microgravity model (16).

MicroRNAs (miRNAs/miRs) are small non-coding RNAs involved in a wide range of biological regulatory processes; a number of studies have shown that numerous miRNAs play important roles in mechanical regulation $(14,17)$ Under microgravity, the mechanosensory miR-103 is upregulated and may inhibit bone formation by targeting runt-related transcription factor 2 (Runx2) during osteoblast differentiation (18). Coincidentally, miR-103 inhibits osteoblast proliferation and bone formation mainly by suppressing the expression of the calcium channel voltage-dependent $L$ type a $1 \mathrm{C}$ subunit, which encodes Cav1.2 under reduced load conditions (19). Thus, under conditions of mechanical load reduction, bone formation may be reduced by changes in miR-103 levels (20). On the other hand, activating the $\mathrm{Wnt} / \beta$-catenin signaling pathway promotes bone formation (21). In AS, the level of dickkopf Wnt signaling pathway inhibitor 1 (DKK1), an inhibitor of the Wnt pathway, is reduced, causing excessive cartilage and bone formation (22). It is unclear whether reducing mechanical load via suspension alleviates the heterotopic ossification of the sacroiliac joint in AS by inhibiting the $\mathrm{Wnt} / \beta$-catenin pathway through miR-103 expression.

The present study aimed to explore the pathogenesis of mechanical load in AS disease and to investigate whether reducing mechanical load, such as suspension, could delay the heterotopic ossification of AS mice. To the best of our knowledge, this is the first study to investigate the therapeutic effect and mechanism of suspension for AS.

\section{Materials and methods}

Animal modeling and suspension for mechanical load reduction intervention. All animal experiments were performed following The Laboratory Animal Care and Use Guidelines of Southern Medical University (23). The experimental scheme was approved by The Institutional Animal Care and Use Committee of Southern Medical University (Guangzhou, China). The reduction of animal suffering during experiments was ensured by continuously monitoring the health status of the animals and applying humane endpoints. The body weight of the experimental animals was measured every month till the end of the experiment. A $20 \%$ loss in body weight over any time period was the humane endpoint criterion used in accoradance with the guidance of Institutional Animal Care and Use Committees (IACUCs) (24).
A total of 50 female specific pathogen-free BALB/c mice (24-week-old; 25.02 23.36 g; Beijing Vital River Laboratory Animal Technology Co., Ltd.) were used in the present study. The proteoglycan (PG)-induced spondylitis (PGIS) mouse model was used $(19,20)$. When the BALB/c mice were 25 weeks old (week 0), they received an intraperitoneal (i.p.) injection with $100 \mathrm{mg}$ of bovine PG (MilliporeSigma) $(25,26)$ as the antigen, combined with Freund's complete adjuvant (MilliporeSigma) in a 1:1 (vol:vol) ratio. Subsequently, the same amount of antigen was injected at weeks 3 and 6 (27). The blank control mice were injected with the same volume of Freund's adjuvant. The mice were maintained in an air-conditioned room ( $60 \pm 5 \%$ relative humidity) with a $12-\mathrm{h}$ light/dark cycle. Water and food were offered ad libitum and the room temperature was maintained at $22-24^{\circ} \mathrm{C}$ with adequate ventilation. After one week of adaptive feeding, female BALB/c mice were randomly assigned to each of the five experimental groups ( $n=10 /$ group), including: i) The mice without PGIS induction (control group); ii) the mice with PGIS induction (PG group); iii) the PGIS mice with tail suspension and no load-bearing (NLB) treatment (PG + NLB group); iv) the PGIS mice with tail suspension and forelimbs touching the floor with the torso $\sim 60^{\circ}$ from the ground to achieve a partial load-bearing (PLB) treatment (PG + PLB group); and v) the PGIS mice subjected to vertical full load-bearing (FLB) intervention, with a small amount of water beneath them so that they remained upright to avoid having their abdomens touching the water (PG + FLB group; Fig. 1).

The experiment was initiated at week 10 after PG induction, followed by continuous intervention for 12 weeks for $6 \mathrm{~h}$ /day. The reduced mechanical load experiments were based on studies that observed simulating microgravity could cause bone loss $(28,29)$. The experiment lasted 22 weeks, and all the mice were euthanized at the end (Fig. 1). $\mathrm{CO}_{2}$ euthanasia was performed using an in-house-designed euthanasia system with a rate of $30 \%$ of the chamber volume $/ \mathrm{min}$.

microCT analysis. At week 12 of PGIS model induction, the mice in the model and control groups were anesthetized via i.p. injection of sodium pentobarbital $(50 \mathrm{mg} / \mathrm{kg})$. microCT imaging and histological analysis was performed to assess the bone morphology in the PGIS mice and to observe the typical characteristics of these mice. Scans of the sacroiliac joint were conducted using a microCT instrument (SCANCO Medical AG) with $80 \mathrm{kV}$ scanning voltage, $180 \mu \mathrm{A}, 9 \mathrm{~W}$ and $12-\mu \mathrm{m}$ scan thickness. For the sacroiliac joint, a 3.1-mm region consisting of 209 slices at the center of the joint were scanned at $15 \mu \mathrm{m}$ nominal voxel size. The two-dimensional images of the joint center were reconstructed using the software in the microCT system. The outcome variables were also analyzed using the microCT.

Histology. After PGIS modeling and experimental interventions, the PG-induced mice were sacrificed. The sacroiliac joint tissue was collected, fixed in 4\% paraformaldehyde for 24-48 h at $4^{\circ} \mathrm{C}$ and decalcified for 3-4 weeks (30). Next, the tissues were embedded in paraffin and cut into $5-\mu \mathrm{m}$ sections. The sections were then dewaxed with xylene and gradient alcohol $(100,95,90,80$ and $70 \%)$, and stained with hematoxylin and eosin (cat. no. G1120; Beijing Solarbio Science \& Technology 

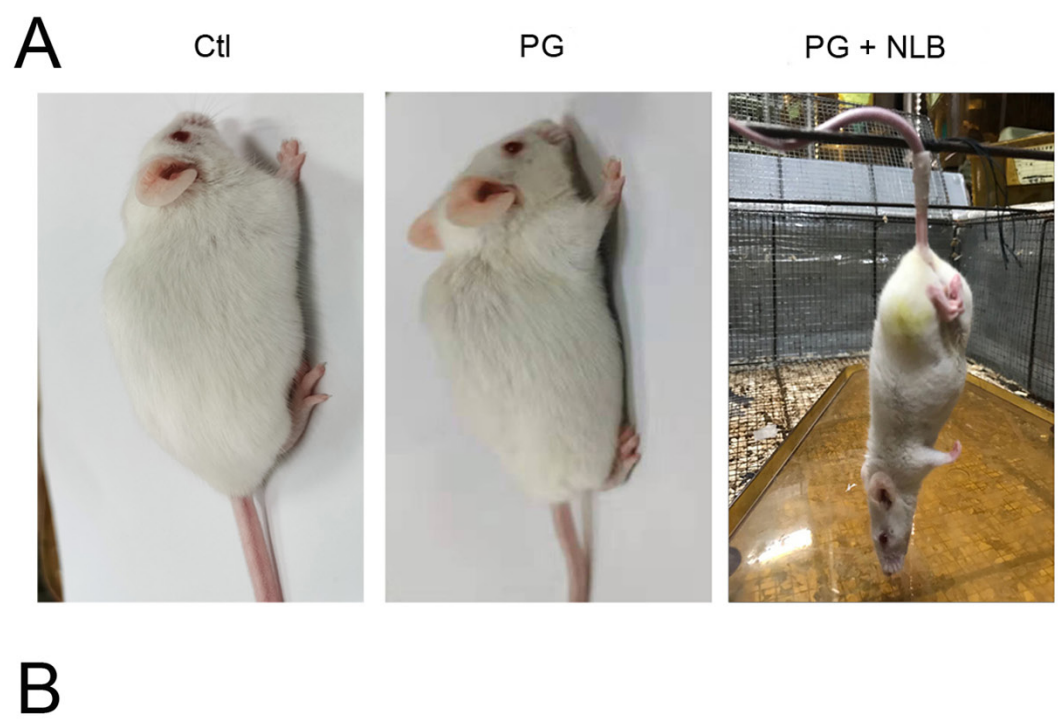

$P G+P L B$
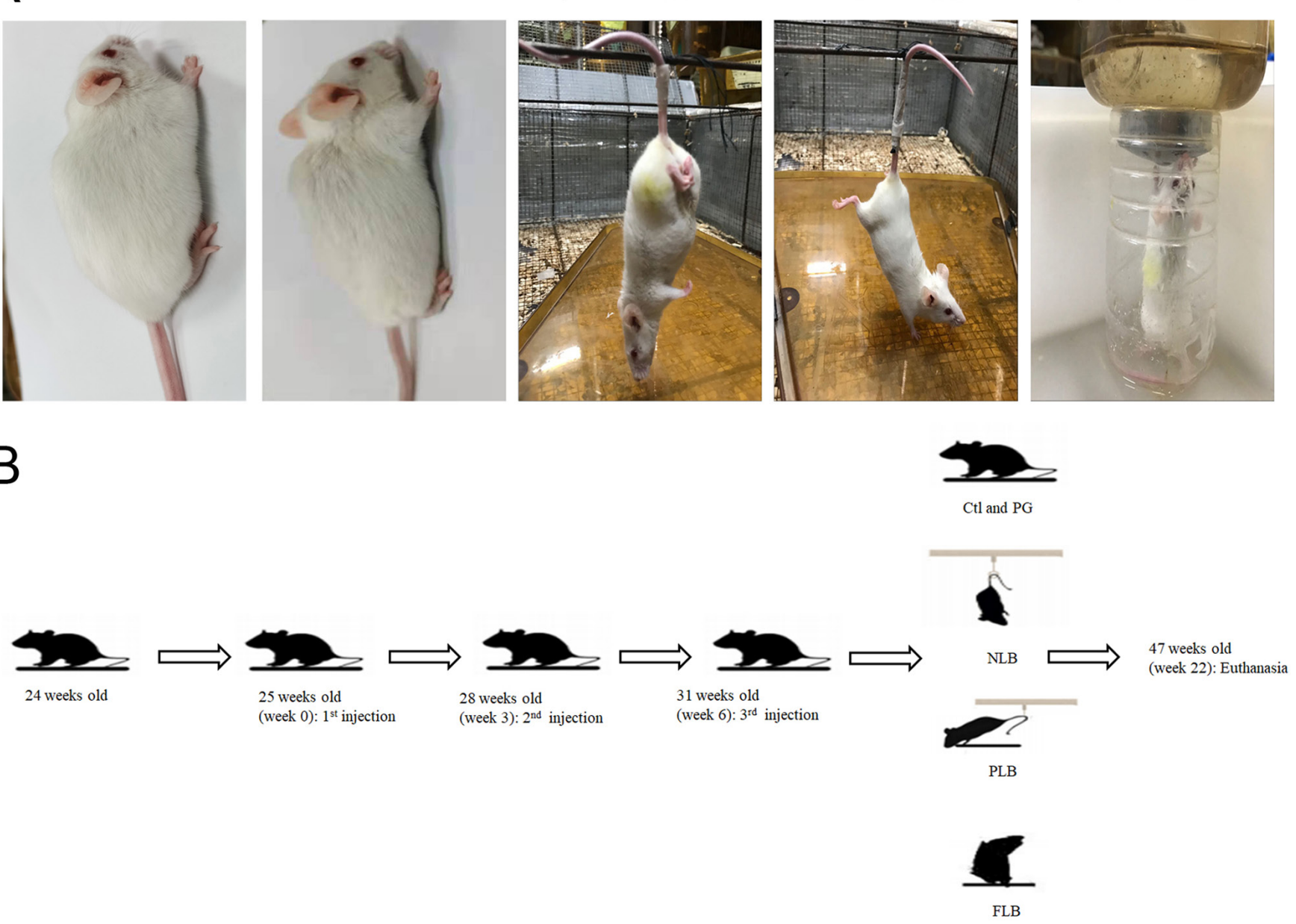

35 weeks old

(week 10): Suspension treatment

Figure 1. Representative images of the mouse groups and experimental design. (A) Ctl, the natural crawling PG-induced group, PG-induced mice with tail suspension for PG + NLB, PG + PLB and vertical PG + FLB groups (n=10/group). (B) Timeline diagram of experimental design. Ctl, control; PG, proteoglycan; FLB, full load bearing; PLB, partial load bearing; NLB, no load bearing.

Co., Ltd.) at room temperature for $30 \mathrm{~min}$. Hematoxylin and eosin (H\&E) staining of the sacroiliac joint demonstrated the typical characteristic changes in the AS model mice (31). Three discontinuous fields of per sample were captured at a magnification of x100-200 using a digital light microscope (Nikon ECLIPSE Ti-S; Nikon Corporation). The percentage of hypertrophic cartilage-like cells was quantified using ImageJ software v.1.51, (National Institutes of Health).

Transfection. The sequence for miR-103 mimic was 5'-AGC AGCAUUGUACAGGGCUAUGA-3', and the nonsense sequence for miR-103 mimic negative control (NC-mimic) was 5'-UUCUCCGAACGUGUCACGUTT-3'. The sequence for miR-103 inhibitor was 5'-TCATAGCCCTGTACAATG CTGCT-3' and the nonsense sequence for miR-103 inhibitor negative control (NC-inhibitor) was 5'-CAGUACUUU UGUGUAGUACAA-3'. The sequences were all designed and synthesized by Guangzhou RiboBio Co., Ltd. The 293T cells (China Center for Type Culture Collection) were transfected with $100 \mathrm{nmol} / \mathrm{l} \mathrm{miR}-103 \mathrm{mimic}$ or NC-mimic using Lipofectamine ${ }^{\circledR} 3000$ transfection reagent (Invitrogen;
Thermo Fisher Scientific, Inc.). The 293T cells were cultured in DMEM (HyClone; Cytiva) with $10 \%$ fetal bovine serum (Gibco; Thermo Fisher Scientific Inc.) at $37^{\circ} \mathrm{C}$ and $5 \% \mathrm{CO}_{2}$ for $24 \mathrm{~h}$. For miR-103 inhibitor groups, the 293T cells were transfected with $100 \mathrm{nmol} / \mathrm{l} \mathrm{miR-103}$ inhibitor and NC-inhibitor using Lipofectamine ${ }^{\circledast} 3000$ transfection reagent for $12 \mathrm{~h}$ at $37^{\circ} \mathrm{C}$. The medium was changed after $12 \mathrm{~h}$ and the cells were incubated for additional 2 days.

Dual luciferase assay. The microRNA.org site (http://www.microrna.org/; v.3.0) predicted that a binding site forhsa-miR-103 was contained within the 3 '-untranslated region (UTR) of the Rockl mRNA. A 3'-UTR luciferase reporter plasmid psiCHECK-2 (Promega Corporation) was constructed for Rock1, and DNA was extracted using a QIAGEN Plasmid kit (QIAGEN $\mathrm{GmbH}$ ) to obtain endotoxin-free plasmid and stored at $-20^{\circ} \mathrm{C}$ until use. $293 \mathrm{~T}$ cells were co-transfected with 20 ng reporter expressing the Rockl-wild-type (WT) 3'-UTR and $100 \mathrm{nmol} / \mathrm{l}$ miR-103 mimics using Lipofectamine ${ }^{\circledR} 3000$ transfection reagent (Invitrogen; Thermo Fisher Scientific Inc.). A Rock1-mutant (Mu) recombinant vector was used as 
Table I. Primers used for quantitative PCR.

\begin{tabular}{lll}
\hline Gene name & \multicolumn{1}{c}{ Forward, 5'-3' } & \multicolumn{1}{c}{ Reverse, $5^{\prime}-3^{\prime}$} \\
\hline Bmp 2 & TCTTCCGGGAACAGATACAGG & TGGTGTCCAATAGTCTGGTCA \\
Runx 2 & GACTGTGGTTACCGTCATGGC & ACTTGGTTTTCATAACAGCGGA \\
Bglap & GAAGCCCAGCGGTGCA & CACTACCTCGCTGCCCTCC \\
miR-103 & GACTGGGGACAGTTTTGAGAC & GGGCATCCAATCCATCCAGC \\
U6 & GCGAGCAGCATTGTACAGGG & AGTGCAGGGTCCGAGGTATT \\
Gapdh & CTCGCTTCGGCAGCACA & AACGCTTCACGAATTTGCGT \\
\end{tabular}

Bmp2, bone morphogenic protein 2; Runx2, runt-related transcription factor 2; Bglap, osteocalcin; Rock1, $\rho$-associated coiled-coil containing protein kinase 1 ; miR, microRNA.

a positive control. The target genes and hsa-miR-103 were co-transfected into $293 \mathrm{~T}$ cells using the cationic liposome method. The interaction between has-miR-103 and the target genes was determined based on luciferase activity. After transfection for $48 \mathrm{~h}$, the fluorescence intensity was detected with dual-luciferase reporter assay system kit (cat. no. K801-200; BioVision, Inc.) and Glomax 20/20 luminometer (Promega, Inc.) according to the manufacturer's protocols and was normalized to that of Renilla luciferase.

Reverse transcription-quantitative $(R T-q) P C R$. The sacroiliac bone tissues from the experimental and control groups were flash-frozen upon collection and stored at $-80^{\circ} \mathrm{C}$ until total RNA extraction using TRIzol ${ }^{\circledR}$ reagent (Takara Bio, Inc.). RNA was reversed transcribed into cDNA and amplified using the systems from Vazyme Biotech Co., Ltd. The cDNA Synthesis kit (cat. no. FSQ-101; Toyobo Life Science) was used to perform RT-qPCR using the following conditions: $15 \mathrm{~min}$ at $37^{\circ} \mathrm{C} ; 5 \mathrm{~min}$ at $98^{\circ} \mathrm{C}$; and $4^{\circ} \mathrm{C}$ hold (32). The RT of miRNA was carried out using the stem-loop method with the same cDNA Synthesis Kit. qPCR was conducted using SYBR Green Master Mix (cat. no. QPK-201; Toyobo Life Science) (32) for the target osteogenic genes (Table I). The thermocycling conditions used were as follows: $95^{\circ} \mathrm{C}$ for $60 \mathrm{sec}$, followed by 40 cycles at $95^{\circ} \mathrm{C}$ for $15 \mathrm{sec}, 60^{\circ} \mathrm{C}$ for $15 \mathrm{sec}$, and $72^{\circ} \mathrm{C}$ for $45 \mathrm{sec}$. The gene expressions were quantified using the comparative threshold cycle $\left(2^{-\Delta \Delta \mathrm{Cq}}\right)$ method (33) and the relative mRNA levels were normalized to the level of Gapdh mRNA. The small nuclear RNA U6 was used as a control for miRNA samples.

IHC. After the PGIS mice underwent 12 weeks of intervention with different mechanical loads, they were sacrificed using $\mathrm{CO}_{2}$. The tissues surrounding the sacroiliac joints were harvested to preserve their integrity. The samples were fixed in $4 \%$ paraformaldehyde at $4^{\circ} \mathrm{C}$ for $24 \mathrm{~h}$, decalcified in EDTA solution for 4 weeks, dehydrated in xylene and descending ethanol (100, 95, 90, 80 and 70\%), paraffin-embedded and cut into $4-\mu \mathrm{m}$ sections. For anti-DKK1 IHC, antigen retrieval was performed using proteinase $\mathrm{K}$ at $20 \mu \mathrm{g} / \mathrm{ml}$ and room temperature for $15 \mathrm{~min}$. After the quenching of endogenous peroxidase with $3 \% \mathrm{H}_{2} \mathrm{O}_{2}$ (cat. no. AR1108; Wuhan Boster Biological Technology, Ltd.), the slides were blocked in TNB buffer (Perkin-Elmer, Inc.) at $37^{\circ} \mathrm{C}$ for $30 \mathrm{~min}$ and stained with the anti-DKK1 antibody (1:200; cat. no. ab61275, Abcam) for $1 \mathrm{~h}$ at room temperature. The sections were washed and incubated with HRP-coupled goat anti-mouse $\operatorname{IgG}$ antibodies (1:500; cat. no. BM3894; Wuhan Boster Biological Technology, Ltd.) at for $30 \mathrm{~min}$ at $37^{\circ} \mathrm{C}$; their signals were amplified using tyramide signal amplification. HRP detection was performed using 3,3'-diaminobenzidine (DAB kit; Invitrogen; Thermo Fisher Scientific Inc.) at room temperature for 2-3 min. The slides were briefly counterstained with hematoxylin at room temperature for $1 \mathrm{~min}$ before mounting. Three discontinuous images per sample were captured at a magnification of x100-200 using a digital light microscope (Nikon ECLIPSE Ti-S; Nikon Corporation). The percentage DKK1-positive cells was quantified using ImageJ software v.1.51 (National Institutes of Health) (34).

Western blotting. The ligaments in the sacroiliac joint obtained from the five different groups and were flash-frozen in liquid nitrogen. RIPA lysis and extraction buffer (cat. no. 89901; Thermo Fisher Scientific, Inc.) containing 50X protease phosphatase inhibitor mix (cat. no. P1045; Beyotime Institute of Biotechnology) was used to lyse the ligament tissues. The samples were then centrifuged at $10,000 \mathrm{x} \mathrm{g}$ and $4^{\circ} \mathrm{C}$ for 10 min to collect the supernatant, which contained the target proteins. A bicinchoninic acid assay kit (cat. no. KGP902; Nanjing KeyGen Biotech Co., Ltd.) was used to detect and adjust protein concentrations.

A total of $10 \mu \mathrm{g} /$ lane target protein were separated via 10-15\% SDS-PAGE gels and transferred to a polyvinylidene difluoride membrane. The membrane was blocked with 5\% BSA (Wuhan Boster Biological Technology, Ltd.) at room temperature for $1 \mathrm{~h}$ and incubated with primary antibodies against ROCK1 (1:1,000; cat. no. ab134181), $\beta$-catenin $(1: 1,000$; cat. no. ab32572), DKK1 (1:1,000; cat. no. ab61275), $\beta$-tubulin (1:1,000; cat. no. ab6046), or Erk1/2 (1:1,000; cat. no. ab17942; all Abcam) or phosphorylated (p-)Erk1/2 (1:1,000; cat. no. 4377; Cell Signaling Technology, Inc.) at $4^{\circ} \mathrm{C}$ overnight. Subsequently, the membrane was incubated with the appropriate horse-radish peroxidase (HRP)-conjugated Goat Anti-Rabbit IgG secondary antibodies (1:5,000; cat. no. BM3894; Wuhan Boster Biological Technology, Ltd.) for $1 \mathrm{~h}$ at room temperature. The level of $\beta$-tubulin was used as a standard internal control. Finally, an enhanced chemiluminescence detection system 
(Thermo Fisher Scientific Inc.) and ChemiDoc Touch Imaging System (Bio-Rad Laboratories, Inc.) were used to identify the relative levels of proteins.

Statistical analysis. Each experiment was performed in triplicate and data were expressed as the mean \pm SD. The statistically significant differences between experimental groups were determined using GraphPad Prism v6.02 (GraphPad Software, Inc.). $\mathrm{P}<0.05$ was considered to indicate a statistically significant difference. Analysis of the relative protein levels and gene expression among the experimental groups was conducted using one-way ANOVA followed by multiple comparisons with Bonferroni's post hoc test.

\section{Results}

Different mechanical interventions cause varying histopathological changes in AS mice. Representative images of different groups in an AS animal model and mechanical interventions are presented below (n=10/group; Fig. 1). The $\mathrm{H} \& \mathrm{E}$ and microCT results indicated the typical characteristic changes of the AS model. Sacroiliac inflammation and hyperplasia in PG-induced mice were noticeable compared with the control group, manifesting as infiltration of inflammatory cell and synovial cells, bone erosion, gap fusion between the bone and cartilage, and significant hypertrophy of cartilage-like cells (Fig. 2A). Furthermore, representative high-resolution microCT images of the sacroiliac spine joint of mice demonstrated that, in the AS model, the sacroiliac space was narrowed and the edges were unclear. The sacroiliac joint bone erosion and joint fusion in tail suspension groups $(\mathrm{PG}+\mathrm{NLB}$ and PG $+\mathrm{PLB})$ were partly relieved compared with the PG group (Fig. 2B); however, the vertical full load-bearing group $(\mathrm{PG}+\mathrm{FLB})$ exhibited aggravated properties. The bone morphometry parameters (BV/TV, Tt.Ar, Ct.Ar and Ct.Th) indicated that bone formation induced by PG could be alleviated by suspension therapy, but exacerbated by full load bearing treatment (Fig. 2B). Taken together, these results suggested a role for mechanical interventions in AS.

The various mechanical interventions were demonstrated to cause significant differences in the levels of the mechanosensory miR-103 compared with the control groups, as presented in Fig. 3A. The PG + NLB and PG + PLB groups exhibited significantly elevated expression of miR-103 compared with the PG-immunized control group, while the PG + FLB group exhibited decreased expression of miR-103. There was a statistically significant difference between the two suspension groups with a reduced mechanical load, the NLB and PLB groups (Fig. 3A). Luciferase assay results indicated that hsa-miR-103 bound to the 3'-UTR end of the mRNA of Rockl-WT in $293 \mathrm{~T}$ cells, thus reducing luciferase activity; conversely, hsa-miR-103 failed to bind to the Rockl-Mu, leaving its fluorescence intensity unchanged (Fig. 3B and C). 293T cells were successfully transfected with miR-103 inhibitor and miR-103 mimics. Further findings indicated that the mRNA expression level of Rock1 was significantly upregulated in $293 \mathrm{~T}$ cells transfected with the miR-103 inhibitor but significantly reduced in cells transfected with miR-103 mimics when compared with their respective NC (Fig. 3D). Meanwhile, the observational PCR results demonstrated that the expression level of Rockl was inhibited by miR-103 in the suspension groups (Fig. 3A and D). Hence, the suspension exerted a significant protective effect against AS through miR-103 and Rock1.

Suspension and load reduction decreases expression of bone formation indicator genes. The expression levels of essential osteogenesis-related genes, such as bone morphogenetic protein-2 (Bmp2), runt-related transcription factor-2 (Runx2) and osteocalcin (Bglap), were analyzed in sacroiliac bone tissues of the five experimental groups using RT-qPCR. Abnormal reductions in bone formation were observed (Fig. 4). The decreased expression of these osteogenesis-related genes in the experimental groups followed a notably similar pattern. The tail suspension groups $(\mathrm{PG}+\mathrm{NLB}$ and $\mathrm{PG}+\mathrm{PLB})$ exhibited significantly downregulated expression of $\mathrm{Bmp2}$, Runx2 and Bglap, which may be associated with the reduced bone formation in sacroiliac joint tissues. Meanwhile, the PG + FLB group exhibited upregulated expression. Although the expression levels of the osteogenic genes were markedly lower in the PG + NLB group compared with the PG + PLB group, the difference between the two groups was not statistically significant for any gene. The above data suggested that suspension and load reduction decreased expression of bone formation indicator genes (Bmp2, Runx2 and Bglap).

Suspension and mechanical load reduction affects the classical osteogenic Wnt/ $\beta$-catenin pathway in AS. The expression level of DKK1 in various experimental groups was analyzed using IHC. It was revealed that the expression of DKK1, a Wnt/ $\beta$-catenin pathway inhibitor, was elevated in the two tail suspension groups (PG + NLB and PG + PLB), but was reduced in the upright $\mathrm{PG}+$ FLB group (Fig. 5). Although the expression level of DKK1 in the PG + NLB group was markedly higher compared with the PG + PLB group, the difference between the two groups was not statistically significant.

Western blotting revealed significantly decreased expression levels of $\beta$-catenin, an essential component of the Wnt/ $\beta$-catenin signaling pathway, in the two tail suspension groups $(\mathrm{PG}+\mathrm{NLB}$ and $\mathrm{PG}+\mathrm{PLB})$ compared with the PG group (Fig. 6). In addition, a significant increase in $\beta$-catenin was observed in the PG + FLB group compared with the PG model group. The level of $\beta$-catenin is positively associated with abnormal bone formation in AS (35). The expression levels of ROCK1 and p-Erk1/2 in the ligaments of the sacroiliac joint were significantly decreased in the groups with suspension with a reduced mechanical load compared with the PG model group, and the opposite trend was observed in the upright group. The expression levels of $\beta$-catenin, ROCK1 and p-Erk in the PG + NLB group appeared to be markedly decreased compared with the PG + PLB group; however, the difference between the two groups was not statistically significant (Fig. 6). Overall, these data suggested that suspension and mechanical load reduction affected the classical osteogenic Wnt/ $\beta$-catenin pathway in AS in vivo.

\section{Discussion}

The present study explored whether mechanical load reduction induced by tail suspension could delay the heterotopic 
A
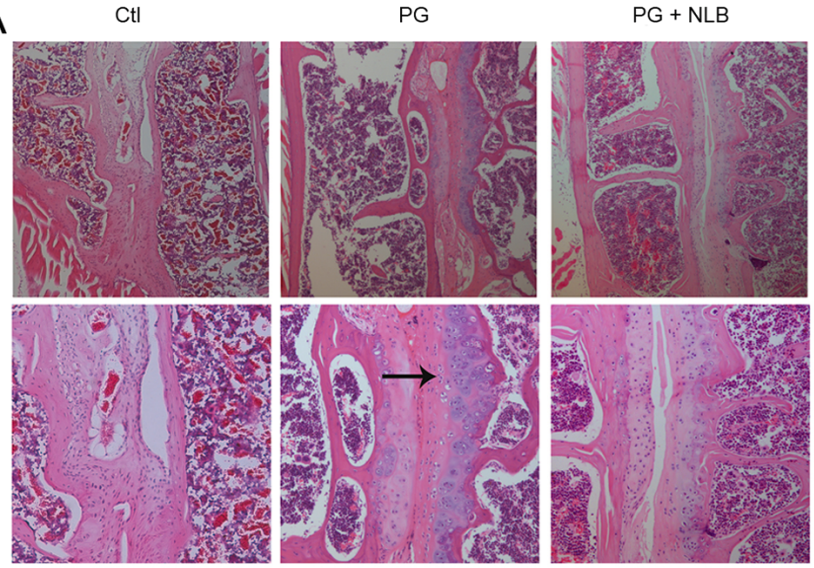
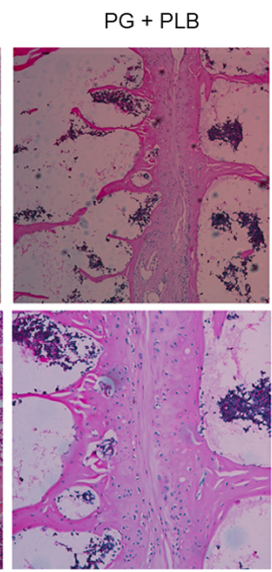

$P G+F L B$

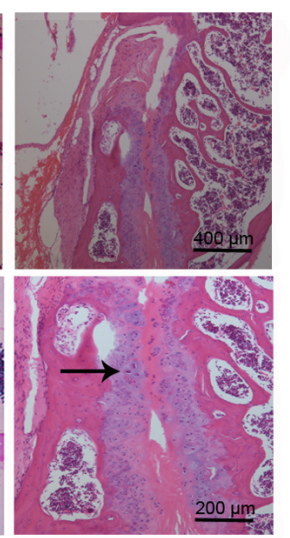

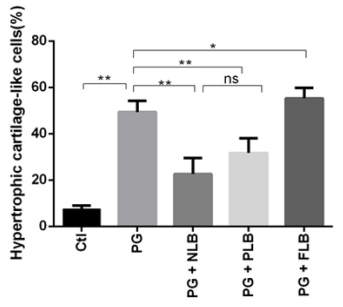

B

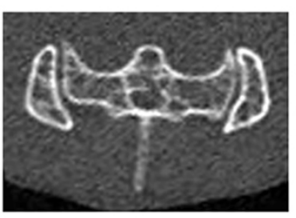

Ctl
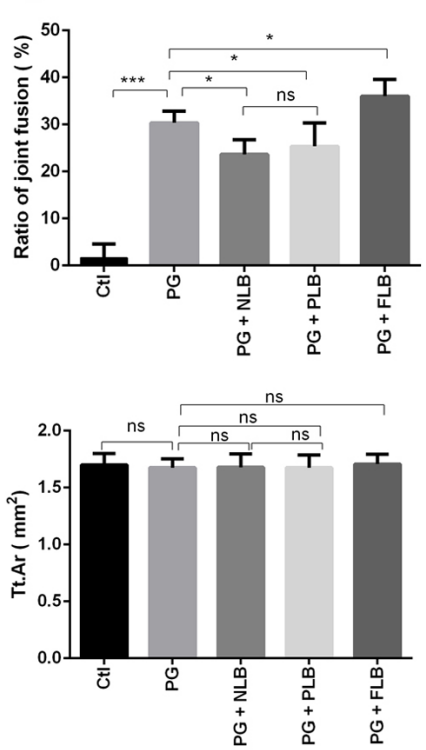

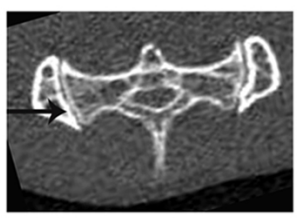

$P G$

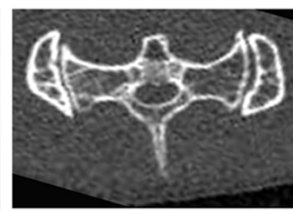

$P G+N L B$
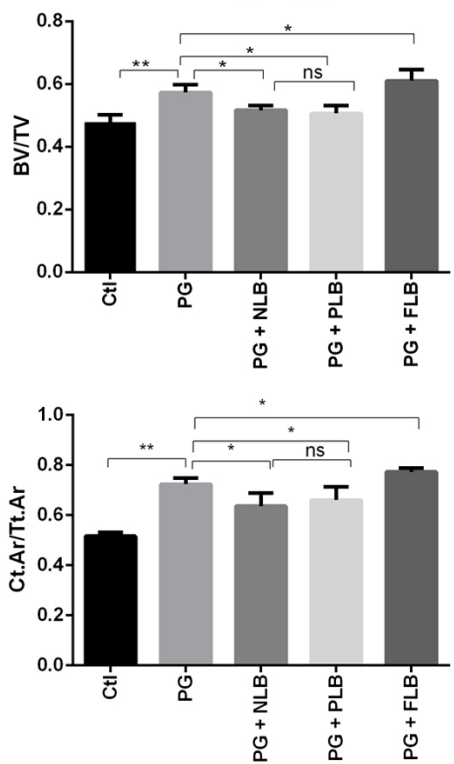

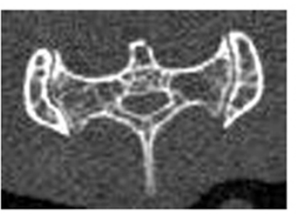

$P G+P L B$
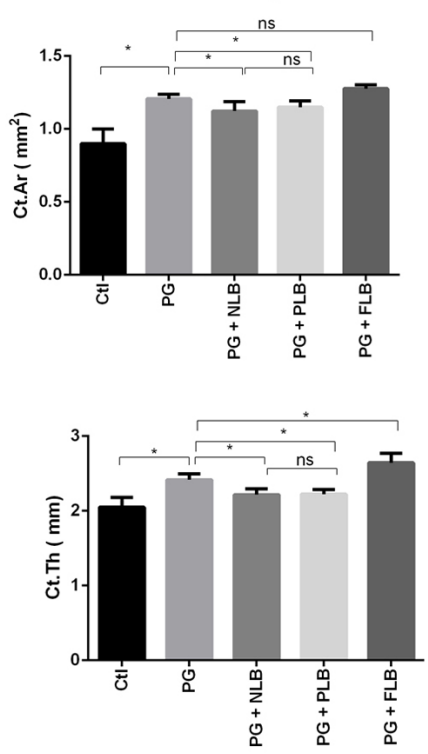

Figure 2. Mechanical load reduction relieves the typical characteristic changes of the AS model. (A) Ctl: H\&E Staining of the sacroiliac joint of control group demonstrated little inflammatory infiltration. PG: Representative H\&E staining of the sacroiliac joints of AS mice demonstrated synovitis, cartilage hyperplasia and bone erosion. Local bone and hypertrophic cartilage hyperplasia filled the entire joint space (arrow; n=4). PG + NLB/PLB: Bone erosion and joint fusion were partially relieved. PG + FLB: Bone erosion of the sacroiliac joint increased. (B) microCT images of the sacroiliac joint from each group. Arrows show the narrowed sacroiliac space and unclear edges $(\mathrm{n}=4){ }^{*} \mathrm{P}<0.05,{ }^{* *} \mathrm{P}<0.01,{ }^{* * *} \mathrm{P}<0.001$. H\&E, hematoxylin and eosin; BV/TV, ratio of the segmented bone volume to the total volume of the region of interest; Tt.Ar, total cross-sectional area; $\mathrm{Ct}$.Ar, cortical bone area; $\mathrm{Ct}$.Th, average cortical thickness; Ctl, control; PG, proteoglycan; NLB, no load bearing; PLB, partial load bearing; FLB, full load bearing; AS, ankylosing spondylitis; ns, not significant.

ossification following enthesitis in AS mice. The results suggested that tail suspension with reduced mechanical load could alleviate pathological bone formation. Furthermore, tail suspension could inhibit the activation of mechanical ROCK1 kinase and the p-Erk1/2 MAPK signaling pathway, and upregulate mechanosensitive miR-103. Meanwhile, the Wnt/ $\beta$-catenin pathway is positively associated with ectopic osteogenesis in AS; furthermore, DKK1, an inhibitor of the Wnt pathway, is increased with a reduced mechanical load, thus inhibiting the activation of the Wnt pathway associated with AS osteogenesis (36).
AS, a chronic autoimmune disease, is characterized by inflammation of the axial skeleton and attachment points, which eventually leads to pathological ossification at attachment sites, including ligaments, tendons and joint capsules (37). This causes the patient to lose normal range of activity (38). Enthesitis and subchondral osteogenesis are the principal factors of inflammation and ossification associated with AS (39). The primary pathological site of AS is the sacroiliac joint; then, it gradually develops and begins to affect the axial spinal joints (40). The axial joints bear heavy loads while maintaining the balance of the pelvis and trunk during 
A

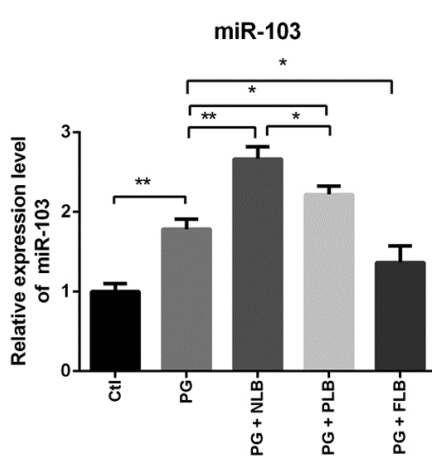

B

ROCK1 5'-acaucagcaagagauAUGCUGCu-3'

IIII II I

hsa-miR-103 3'-aguaucgggacauguUACGACGa-5'

IIIIIII

ROCK1 Mut - $5^{\prime}$ acaucagcaagagauCCUAGCUu- $3^{\prime}$

C

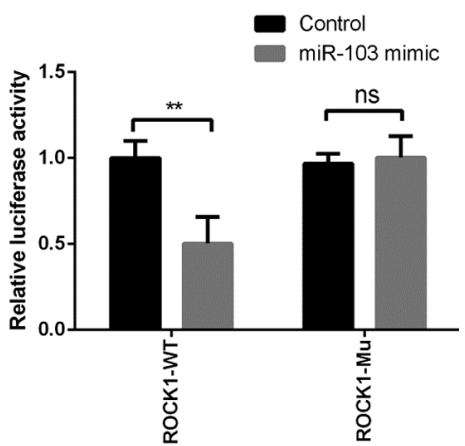

D

ROCK1

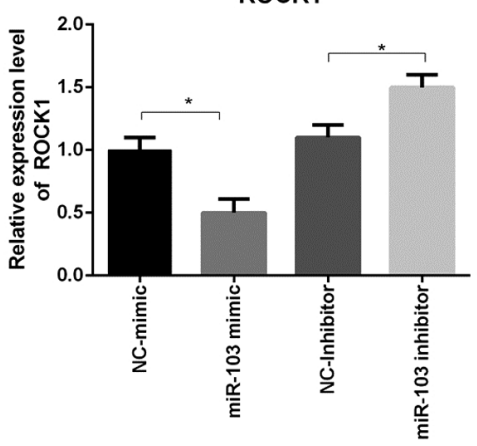

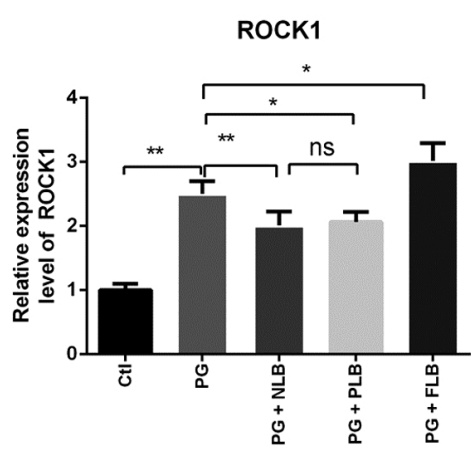

Figure 3. miR-103 expression is increased in the tail suspension group and may affect the pathological ossification of AS by combining with the 3'-UTR of ROCK1. (A) Expression levels of miR-103 were increased in the PG + NLB and PG + PLB groups compared with the PG group, while the PG + FLB group demonstrated decreased expression levels. (B) Alignment of miR-103 with the 3'-UTR of Rock1. (C) 293T cells were co-transfected with a reporter expressing the Rockl-WT 3'-UTR and miR-103 mimics. Rockl-Mu recombinant vector was used as a positive control and targeting effect was measured using luciferase activity. (D) mRNA expression of Rock1 in $293 \mathrm{~T}$ cells (left) and in vivo (right) transfected with miR-103 mimics or miR-103 inhibitor. ${ }^{*} \mathrm{P}<0.05,{ }^{* *} \mathrm{P}<0.01$. miR, microRNA; Rock1, $\rho$-associated coiled-coil containing protein kinase 1; UTR, untranslated region; WT, wild-type; Mu, mutant; AS, ankylosing spondylitis; PG, proteoglycan; Ctl, control; NLB, no load bearing; PLB, partial load bearing; FLB, full load bearing; ns, not significant; NC, negative control.
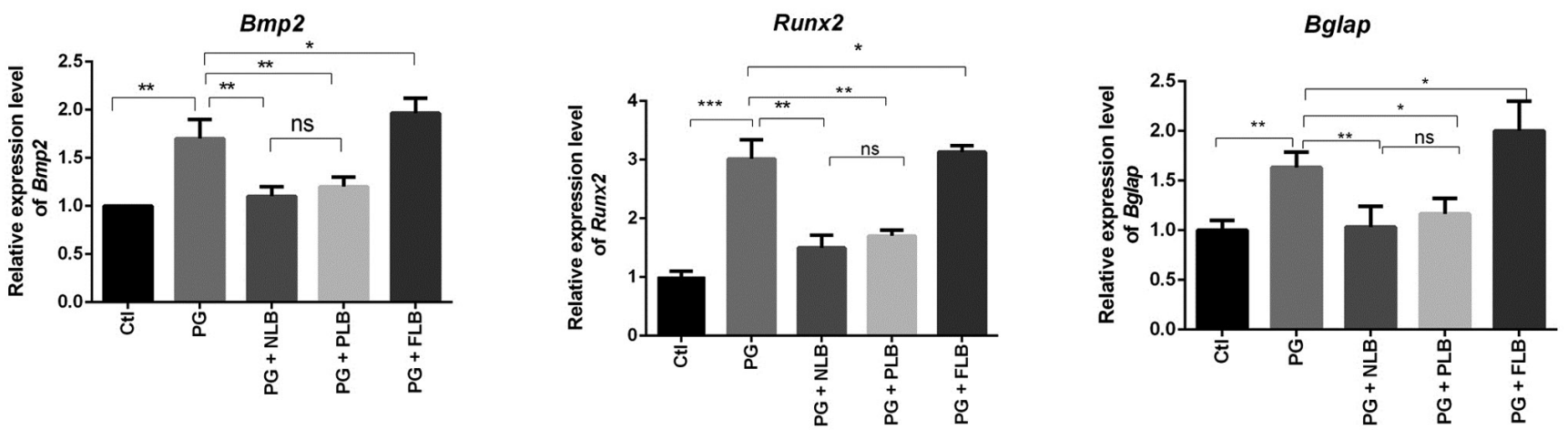

Figure 4. RT-qPCR results of sacroiliac joint bone tissue indicate that tail suspension reduces osteogenesis, while upright intervention increases osteogenesis. RT-qPCR analysis demonstrated that the expression levels of osteo-specific genes (Bmp2, Runx2 and Bglap) were decreased in the PG + NLB and PG + PLB groups, whereas the expression of osteogenic genes in the PG + FLB group exhibited opposing trends $(\mathrm{n}=3) .{ }^{*} \mathrm{P}<0.05,{ }^{* * *} \mathrm{P}<0.01 ;{ }^{* * * *} \mathrm{P}<0.001 . B m p 2$, bone morphogenetic protein 2; Runx2, runt-related transcription factor 2; Bglap, osteocalcin; ns, not significant; Ctl, control; PG, proteoglycan; NLB, no load bearing; PLB, partial load bearing; FLB, full load bearing; RT-qPCR, reverse transcription-quantitative PCR.

daily activities (41). Long-term axial overload will increase micro-injury of the sacroiliac and spinal joints, leading to a repair process that causes synovitis, joint destruction and late-stage subchondral bone rigidity (42). The increased mechanical load could be a significant cause of ectopic bone formation, which often occurs in AS, and can lead to joint fusion and stiffness (6). Career-associated high-intensity mechanical stress has been reported to accelerate immune joint injury (6). Studies indicated that an excessive mechanical load can lead to the progression of AS in patients with an active background, such as athletes (37), according to several lines of evidence $(6,37)$. For example, spinal overloading could predispose patients to enhanced sacroiliac joint damage and repair pathways, leading to synovitis, erosions, and pathological ossification $(6,43,44)$. On the other hand, previous studies have shown that patients who remain in bed for an extended period may experience bone loss due to disuse and reduced bone formation $(45,46)$. 

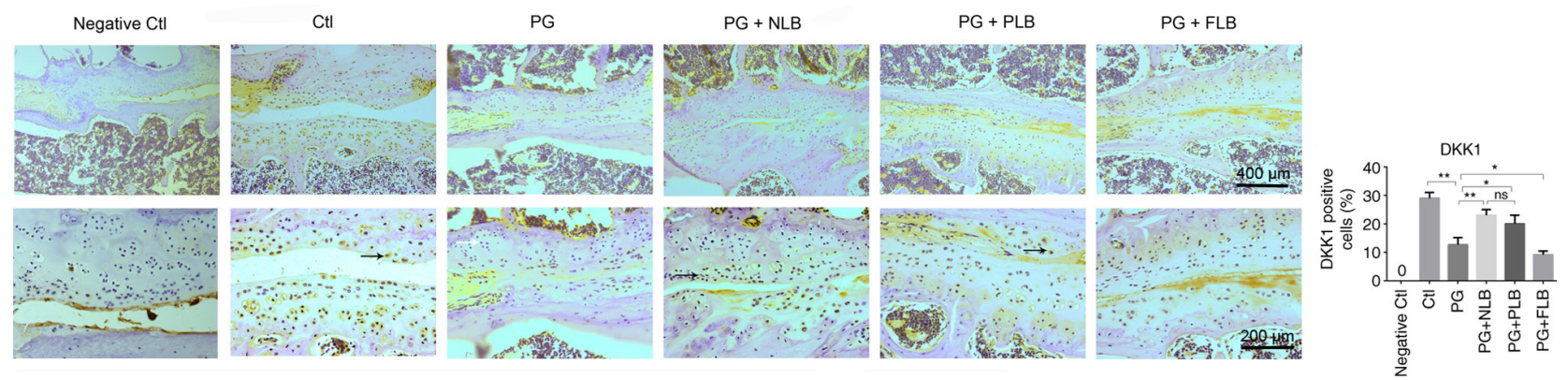

Figure 5. Reduced mechanical load upregulates the expression of Wnt pathway inhibitor DKK1. DKK1-positive cells were quantified using ImageJ software. Immunohistochemistry analysis indicated that PG + NLB and PG + PLB groups increased DKK1-positive expression compared with the PG group, while the PG + FLB group exhibited lower DKK1 expression levels (n=4). Scale bar: Top row, $400 \mu \mathrm{m}$; bottom row, $200 \mu \mathrm{m}$; ${ }^{*} \mathrm{P}<0.05$, " $\mathrm{P}<0.01$. DKK1, dickkopf Wnt signaling pathway inhibitor 1; Ctl, control; PG, proteoglycan; NLB, no load bearing; PLB, partial load bearing; FLB, full load bearing; ns, not significant.
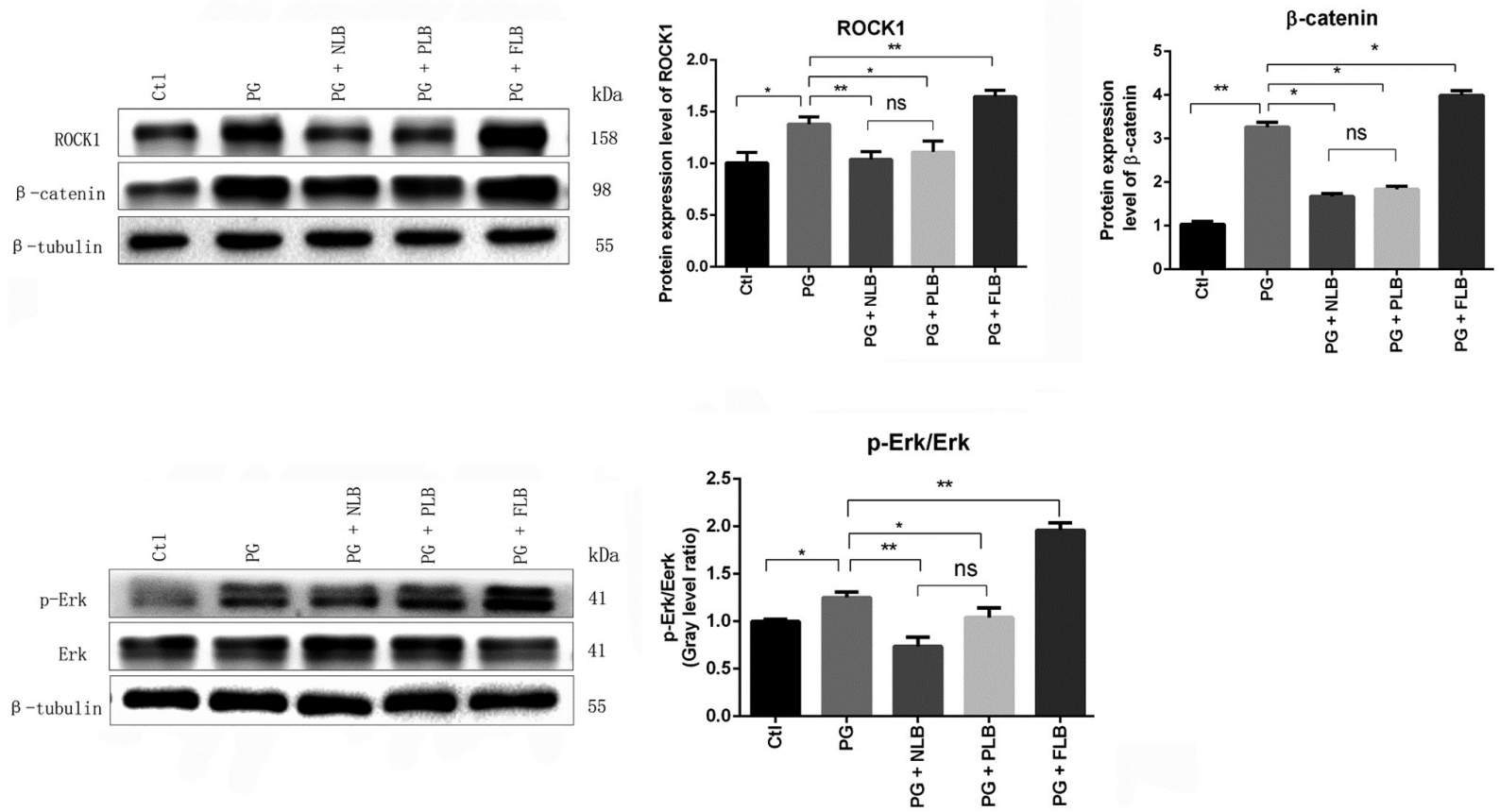

Figure 6. Changes in the mechanical pathway proteins ROCK1 and p-Erk1/2 MAPK and osteogenic Wnt/ $\beta$-catenin pathway proteins. Western blotting and quantitative data demonstrated reduced expression levels of ROCK1, p-Erk/Erk and $\beta$-catenin in the PG + NLB and PG + PLB groups, and an increase in these expressions in the PG + FLB group compared with the PG group. " $\mathrm{P}<0.05,{ }^{* *} \mathrm{P}<0.01$. ROCK1, $\rho$-associated coiled-coil containing protein kinase 1; MAPK, mitogen-activated protein kinase; p-, phosphorylated; Ctl, control; PG, proteoglycan; NLB, no load bearing; PLB, partial load bearing; FLB, full load bearing; ns, not significant.

The pathogenesis of AS has not yet been fully elucidated. Inflammation is generally associated with tissue destruction, such as ankylosis following new cartilage and bone formation (47). Also, the activation of TNF- $\alpha$ (48) and the IL-23/IL-17 pathway (49) are known to play critical roles in the inflammatory response in AS (50). An autoimmune disorder marker, human leukocyte antigen B27, exhibits the strongest association with AS $(51,52)$, but its relationship with AS has not been firmly established. Thus, the treatment of AS has utilized non-steroidal anti-inflammatory drugs and anti-rheumatic biologics in recent years (53). The biological agents approved for the treatment of AS include TNF- $\alpha$ and IL-17 inhibitors, which are the subjects of intense research focus (53). On the other hand, severe dysfunction is treated with orthopedic surgery. However, no method has been shown to delay the progression of AS (47). Furthermore, the impact of biomechanical stress on AS, and the link between AS and biomechanics, remain unclear. Early space flight experiments have indicated that the musculoskeletal system is highly sensitive to gravity loading (54). Recently, mouse tail suspension used as a model to simulate the reduction of mechanical stress has also been reported to reduce bone formation in mice (55). Therefore, the present study aimed to understand if tail suspension could be used to delay the progress of AS.

The effect of tail suspension on the progression of AS was investigated by monitoring changes in the expression of genes involved in osteogenesis. RT-qPCR analysis revealed that the expression levels of bone formation-related marker genes, including Bmp2, Runx2 and Bglap, in sacroiliac bone tissues were decreased in the tail suspension groups. By contrast, the expression levels of these markers were increased in the vertical FLB group. In AS, the molecules involved in bone 
formation, such as Wnt and its antagonist DKK1, may drive syndesmophyte formation (56). The Wnt/ $\beta$-catenin signaling pathway is known to respond to the mechanical loading of bones (57). Reduced DKK1 expression levels cause hyperplasia of the tissues surrounding the joint, which is associated with stiffness presenting as sacroiliitis (58). In the present study, IHC analysis revealed that the expression of DKK1 was upregulated in the tail suspension groups (PG + NLB and PG + PLB), indicating suppression of the classical $\mathrm{Wnt} / \beta$-catenin pathway and thus inhibition of osteophyte formation at sacroiliac joints in AS. The upregulation of DKK1 under reduced mechanical stress indicates remission of AS (59). $\beta$-catenin is a critical protein in the classical Wnt signaling pathway that plays a central role in the formation of ectopic bone (10). Moreover, the production of $\beta$-catenin is positively associated with AS osteogenesis (60). The present study revealed that $\beta$-catenin levels were upregulated in the AS model (PG) and downregulated in the groups with a reduced mechanical load (PG + NLB and PG + PLB), which was consistent with previous studies (10). These data suggested that reducing mechanical load could inhibit AS heterotopic bone formation.

Available evidence indicates that increasing mechanical stress can significantly promote the activation of the $\mathrm{p}$-Erk1/2 MAPK and Wnt/ $\beta$-catenin signaling pathways (18). Also, the mechanical stress-induced cell response depends on the effector ROCK1/2 and Erk1/2 pathways (61). $\rho$ kinase activates phosphorylation of Erk1/2 in MAPK signaling by regulating ROCK1/2 with increasing biological load (62). Thus, ROCK1 is an upstream regulator of the MAPK signaling pathway, and p-Erk $1 / 2$ activates the $\mathrm{Wnt} / \beta$-catenin pathway by promoting GSK-3 $\beta$ phosphorylation $(12,63)$. Consistent with the known activation of the $\mathrm{p}$-Erk1/2 MAPK and $\mathrm{Wnt} / \beta$-catenin signaling pathways by increasing mechanical stress (18), western blotting during the present study indicated that the levels of ROCK1, p-Erk $1 / 2$ and $\beta$-catenin were decreased in the groups with reduced mechanical load $(\mathrm{PG}+\mathrm{NLB}$ and $\mathrm{PG}+\mathrm{PLB})$. This finding indicated that tail suspension may inhibit MAPK and Wnt/ $\beta$-catenin signaling pathways by reducing the expression of ROCK1. In addition, the standing group that was bearing a greater load demonstrated the opposing trend, with increases in the expression levels of osteogenic genes and mechanical pathway proteins.

As miR-103 mainly inhibits osteoblast proliferation by inhibiting the expression of Cav1.2 and Runx2 under simulated microgravity conditions $(18,19)$, the expression of miR-103 was evaluated under different experimental conditions. Tail suspension and simulating reduced mechanical load upregulated the expression level of miR-103 and reduced the expression of osteogenic genes, consistent with the inhibition of bone formation in the sacroiliac joints in AS. Dual-luciferase assays verified that miR-103 would bind to the 3'-UTR end of Rockl. Thus, the increased expression levels of miR-103 in the tail suspension groups with reduced mechanical load negatively regulated the activity of ROCK1, which affected the pathological ossification in AS.

In summary, the present study performed various interventions, including tail suspensions for reduced mechanical load and full upright load-bearing, in AS model mice. It was revealed that under reduced mechanical load conditions, the expression levels of osteogenesis-related genes and mechanical pathway signals were decreased, and the expression of the osteogenic Wnt pathway inhibitor DKK1 was increased, indicating reduced bone formation. However, the difference between the PG + NLB and PG + PLB groups was not statistically significant. Furthermore, tail suspension affected control of the mechanical kinase ROCK 1 and p-Erk1/2 in the MAPK pathway by upregulating the expression of miR-103, further suppressing the osteogenic Wnt/ $\beta$-catenin pathway associated with AS. The results indicated that reducing mechanical stress could delay ectopic osteogenesis in the sacroiliac joint by regulating the Wnt pathway and its inhibitor DKK1, thereby delaying the progression of AS.

The current study investigated the effect of reducing mechanical stress on AS mice and examined its potential as a basis for clinical therapy. For humans, spinal traction is a common clinical treatment for reducing mechanical stress, which is similar to suspension (64). The findings supported spinal traction as a novel therapeutic option for AS treatment. However, further studies are required to delineate the role of reducing mechanical stress in the pathology of AS. In the future, it will be of interest to confirm these findings in a clinical setting. Also, it will be valuable to examine the immune-related pathological processes of osteogenesis. However, the present study had several limitations. Although a close relationship between miR-103 and ROCK1 by miR-103 mimic and inhibitor was demonstrated in vitro, the effect of miR-103 expression on ROCK1 must be verified in vivo by future studies. The present study used PG-induced mice rather than patients with AS to assess the expression levels of miR-103 and ROCK1.

In conclusion, the results demonstrated that mechanical load played a notable role in ectopic bone formation and AS progression. Tail suspension resulting in reduced mechanical load alleviated ectopic osteogenesis in the sacroiliac joints of AS mice by upregulating the expression of miR-103, suppressing mechanical signaling pathways and inhibiting the classical Wnt/ $\beta$-catenin pathway involved in bone formation. In summary, tail suspension to reduce mechanical stress offers a promising adjuvant therapy for attenuating ectopic bone formation associated with $\mathrm{AS}$ and requires further investigation.

\section{Acknowledgements}

Not applicable.

\section{Funding}

The present study was supported by The Natural Science Foundation of Guangdong Province (grant no. 2017A030313721), The National Natural Science Foundation of China (grant no. 81774382) and the Scientific Research Project of Traditional Chinese Medicine Bureau of Guangdong Province (grant no. 20181175).

\section{Availability of data and materials}

All data generated or analyzed during this study are included in this published article. 


\section{Authors' contributions}

GL and YZ designed the experiments. ZZ and JZ performed the experiments and wrote the manuscript. QL and YL analyzed the data. $\mathrm{DH}$ analyzed the data and revised the manuscript. GL and ZZ confirmed the authenticity of all the raw data. All authors have read and approved the final manuscript.

\section{Ethics approval and consent to participate}

The experimental scheme was approved by The Institutional Animal Care and Use Committee of the Southern Medical University (Guangzhou, China).

\section{Patient consent for publication}

Not applicable.

\section{Competing interests}

The authors declare that they have no competing interests.

\section{References}

1. Ma S, Wang DD, Ma CY and Zhang YD: MicroRNA-96 promotes osteoblast differentiation and bone formation in ankylosing spondylitis mice through activating the Wnt signaling pathway by binding to SOST. J Cell Biochem 120: 15429-15442, 2019.

2. Lories RJ and Haroon N: Evolving concepts of new bone formation in axial spondyloarthritis: Insights from animal models and human studies. Best Pract Res Clin Rheumatol 31: 877-886, 2017.

3. Carter S, Braem K and Lories RJ: The role of bone morphogenetic proteins in ankylosing spondylitis. Ther Adv Musculoskelet Dis 4: 293-299, 2012.

4. Sieper J and Poddubnyy D: Axial spondyloarthritis. Lancet 390: 73-84, 2017.

5. Voirin-Hertz M, Carvajal Alegria G, Garrigues F, Simon A, Feydy A, Reijnierse M, van der Heijde D, Loeuille D, Claudepierre P, Marhadour T and Saraux A: Associations of lumbar scoliosis with presentation of suspected early axial spondyloarthritis. Semin Arthritis Rheum 50: 48-53, 2020.

6. Masi AT: Might axial myofascial properties and biomechanical mechanisms be relevant to ankylosing spondylitis and axial spondyloarthritis? Arthritis Res Ther 16: 107, 2014.

7. Hoch AI, Mittal V, Mitra D, Vollmer N, Zikry CA and Leach JK: Cell-secreted matrices perpetuate the bone-forming phenotype of differentiated mesenchymal stem cells. Biomaterials 74 178-187, 2016.

8. Mu C, Lv T, Wang Z, Ma S, Ma J, Liu J, Yu J and Mu J: Mechanical stress stimulates the osteo/odontoblastic differentiation of human stem cells from apical papilla via erk $1 / 2$ and JNK MAPK pathways. Biomed Res Int 2014: 494378, 2014.

9. Van Mechelen M, Gulino GR, de Vlam K and Lories R: Bone disease in axial spondyloarthritis. Calcif Tissue Int 102: 547-558, 2018.

10. Li X, Wang J, Zhan Z, Li S, Zheng Z, Wang T, Zhang K, Pan H, Li Z, Zhang $\mathrm{N}$ and Liu $\mathrm{H}$ : Inflammation intensity-dependent expression of osteoinductive Wnt proteins is critical for ectopic new bone formation in ankylosing spondylitis. Arthritis Rheumatol 70: 1056-1070, 2018.

11. Zou YC, Yang XW, Yuan SG, Zhang P, Ye YL and Li YK: Downregulation of dickkopf-1 enhances the proliferation and osteogenic potential of fibroblasts isolated from ankylosing spondylitis patients via the Wnt/ $\beta$-catenin signaling pathway in vitro. Connect Tissue Res 57: 200-211, 2016.

12. Appleton CT, Usmani SE, Mort JS and Beier F: Rho/ROCK and MEK/ERK activation by transforming growth factor-alpha induces articular cartilage degradation. Lab Invest 90: 20-30, 2010

13. Millner JR, Barron JS, Beinke KM, Butterworth RH, Chasle BE Dutton LJ, Lewington MA, Lim EG, Morley TB, O'Reilly JE, et al: Exercise for ankylosing spondylitis: An evidence-based consensus statement. Semin Arthritis Rheum 45: 411-427, 2016.
14. Chen Y, Xu J, Yang C, Zhang H, Wu F, Chen J, Li K, Wang H, $\mathrm{Li}$ Y, Li Y and Dai Z: Upregulation of miR-223 in the rat liver inhibits proliferation of hepatocytes under simulated microgravity. Exp Mol Med 49: e348, 2017.

15. Wang J, Liu C, Li T, Wang Y and Wang D: Proteomic analysis of pulmonary tissue in tail-suspended rats under simulated weightlessness. J Proteomics 75: 5244-5253, 2012.

16. Liu J, Wang J and Guo Y: Effect of collagen peptide, alone and in combination with calcium citrate, on bone loss in tail-suspended rats. Molecules 25: 782, 2020.

17. Stadnik PS, Gilbert SJ, Tarn J, Charlton S, Skelton AJ, Barter MJ, Duance VC, Young DA and Blain EJ: Regulation of microRNA-221, -222, -21 and -27 in articular cartilage subjected to abnormal compressive forces. J Physiol 599: $143-155,2021$.

18. Zuo B, Zhu J, Li J, Wang C, Zhao X, Cai G, Li Z, Peng J, Wang P, Shen C, et al: microRNA-103a functions as a mechanosensitive microRNA to inhibit bone formation through targeting Runx2. J Bone Miner Res 30: 330-345, 2015.

19. Sun Z, Cao X, Hu Z, Zhang L, Wang H, Zhou H, Li D, Zhang S and Xie M: miR-103 inhibits osteoblast proliferation mainly through suppressing Cav1.2 expression in simulated microgravity. Bone 76: 121-128, 2015.

20. Lv H, Yang $\mathrm{H}$ and Wang Y: Effects of miR-103 by negatively regulating SATB2 on proliferation and osteogenic differentiation of human bone marrow mesenchymal stem cells. PLoS One 15: $\mathrm{e} 0232695,2020$.

21. Zheng L, Hu F, Bian W, Li Y, Zhang L, Shi L, Ma X, Liu Y, Zhang $X$ and Li Z: Dickkopf-1 perpetuated synovial fibroblast activation and synovial angiogenesis in rheumatoid arthritis. Clin Rheumatol: May 19, 2021 (Epub ahead of print).

22. Haynes KR, Pettit AR, Duan R, Tseng HW, Glant TT, Brown MA and Thomas GP: Excessive bone formation in a mouse model of ankylosing spondylitis is associated with decreases in Wnt pathway inhibitors. Arthritis Res Ther 14: R253, 2012.

23. Liu JH, Wang Q, You QL, Li ZL, Hu NY, Wang Y, Jin ZL, Li SJ, Li XW, Yang JM, et al: Acute EPA-induced learning and memory impairment in mice is prevented by DHA. Nat Commun 11: 5465,2020

24. Sanders CJ, Johnson B, Frevert CW and Thomas PG: Intranasal influenza infection of mice and methods to evaluate progression and outcome. Methods Mol Biol 1031: 177-188, 2013.

25. Qin J, Li J, Yang H, Jia M, Li X, Yao Q, Zhang Y, Zhu J and Li C: Values of intravoxel incoherent motion diffusion weighted imaging and dynamic contrast-enhanced MRI in evaluating the activity of sacroiliitis in ankylosing spondylitis of rat model. Magn Reson Imaging 68: 30-35, 2020.

26. Ishikawa LL, Colavite PM, da Rosa LC, Balbino B, França TG, Zorzella-Pezavento SF, Chiuso-Minicucci F and Sartori A: Commercial bovine proteoglycan is highly arthritogenic and can be used as an alternative antigen source for PGIA model. Biomed Res Int 2014: 148594, 2014.

27. He T, Huang Y, Zhang C, Liu D, Cheng C, Xu W and Zhang X: Interleukin-17A-promoted MSC2 polarization related with new bone formation of ankylosing spondylitis. Oncotarget 8: 96993-97008, 2017.

28. Shanmugarajan S, Zhang Y, Moreno-Villanueva M, Clanton R, Rohde LH, Ramesh GT, Sibonga JD and Wu H: Combined effects of simulated microgravity and radiation exposure on osteoclast cell fusion. Int J Mol Sci 18: 2443, 2017.

29. Wang Y, Zhao W, Shi J, Wang J, Hao J, Pang X, Huang X, Chen X, Li Y, Jin R and Ge Q: Intestinal microbiota contributes to altered glucose metabolism in simulated microgravity mouse model. FASEB J 33: 10140-10151, 2019.

30. Liang S, Wang ZG, Zhang ZZ, Chen K, Lv ZT, Wang YT, Cheng P, Sun K, Yang Q and Chen AM: Decreased RIPK1 expression in chondrocytes alleviates osteoarthritis via the TRIF/MyD88-RIPK1-TRAF2 negative feedback loop. Aging (Albany NY) 11: 8664-8680, 2019.

31. Ahmadvand Koohsari S, Absalan A and Azadi D: Human umbilical cord mesenchymal stem cell-derived extracellular vesicles attenuate experimental autoimmune encephalomyelitis via regulating pro and anti-inflammatory cytokines. Sci Rep 11: $11658,2021$.

32. Liang S, Zhang JM, Lv ZT, Cheng P, Zhu WT and Chen AM: Identification of Skt11-regulated genes in chondrocytes by integrated bioinformatics analysis. Gene 677: 340-348, 2018.

33. Livak KJ and Schmittgen TD: Analysis of relative gene expression data using real-time quantitative PCR and the 2(-Delta Delta C(T)) method. Methods 25: 402-408, 2001. 
34. Hao X, Wang S, Zhang J and Xu T: Effects of body weight-supported treadmill training on cartilage-subchondral bone unit in the rat model of posttraumatic osteoarthritis. J Orthop Res 39: 1227-1235, 2021.

35. He X and Dong Y: Ankylosis progressive homolog upregulation inhibits cell viability and mineralization during fibroblast ossification by regulating the Wnt/ $\beta$-catenin signaling pathway. Mol Med Rep 22: 4551-4560, 2020.

36. Klavdianou K, Liossis SN, Sakkas L and Daoussis D: The role of dickkopf-1 in joint remodeling and fibrosis: A link connecting spondyloarthropathies and scleroderma? Semin Arthritis Rheum 46: 430-438, 2017.

37. Benjamin M, Toumi H, Ralphs JR, Bydder G, Best TM and Milz S: Where tendons and ligaments meet bone: Attachment sites ('entheses') in relation to exercise and/or mechanical load. J Anat 208: 471-490, 2006

38. Regnaux JP, Davergne T, Palazzo C, Roren A, Rannou F, Boutron I and Lefevre-Colau MM: Exercise programmes for ankylosing spondylitis. Cochrane Database Syst Rev 10: CD011321, 2019.

39. Jo S, Won EJ, Kim MJ, Lee YJ, Jin SH, Park PR, Song HC, Kim J, Choi YD, Kim JY, et al: STAT3 phosphorylation inhibition for treating inflammation and new bone formation in ankylosing spondylitis. Rheumatology (Oxford): Nov 25, 2020 (Epub ahead of print).

40. Soulard J, Vaillant J, Agier CT and Vuillerme N: Gait characteristics in patients with ankylosing spondylitis: A systematic review. Clin Exp Rheumatol 39: 173-186, 2021.

41. Sturdy JT, Sessoms PH and Silverman AK: A backpack load sharing model to evaluate lumbar and hip joint contact forces during shoulder borne and hip belt assisted load carriage. Appl Ergon 90: 103277, 2021.

42. Herrero-Beaumont G, Pérez-Baos S, Sánchez-Pernaute O, Roman-Blas JA, Lamuedra A and Largo R: Targeting chronic innate inflammatory pathways, the main road to prevention of osteoarthritis progression. Biochem Pharmacol 165: 24-32, 2019

43. Francois RJ, Gardner DL, Degrave EJ and Bywaters EG: Histopathologic evidence that sacroiliitis in ankylosing spondylitis is not merely enthesitis. Arthritis Rheum 43: 2011-2024, 2000.

44. Vleeming A, Schuenke MD, Masi AT, Carreiro JE, Danneels L and Willard FH: The sacroiliac joint: An overview of its anatomy, function and potential clinical implications. J Anat 221: 537-567, 2012.

45. Bi D, Dai Z, Liu D, Wu F, Liu C, Li Y, Li B, Li Z, Li Y and Ta D: Ultrasonic backscatter measurements of human cortical and trabecular bone densities in a head-down bed-rest study. Ultrasound Med Biol: May 26, 2021 (Epub ahead of print).

46. Rolvien T, Milovanovic P, Schmidt FN, von Kroge S, Wölfel EM, Krause M, Wulff B, Püschel K, Ritchie RO, Amling M and Busse B: Long-term immobilization in elderly females causes a specific pattern of cortical bone and osteocyte deterioration different from postmenopausal osteoporosis. J Bone Miner Res 35: 1343-1351, 2020.

47. Braem K and Lories RJ: Insights into the pathophysiology of ankylosing spondylitis: Contributions from animal models. Joint Bone Spine 79: 243-248, 2012

48. Lubrano E, Spadaro A, Amato G, Benucci M, Cavazzana I, Chimenti MS, Ciancio G, D Alessandro G, Angelis R, Lupoli S, et al: Tumour necrosis factor alpha inhibitor therapy and rehabilitation for the treatment of ankylosing spondylitis: A systematic review. Semin Arthritis Rheum 44: 542-550, 2015.

49. Gravallese EM and Schett G: Effects of the IL-23-IL-17 pathway on bone in spondyloarthritis. Nat Rev Rheumatol 14: 631-640, 2018.
50. McGonagle DG, McInnes IB, Kirkham BW, Sherlock J and Moots R: The role of IL-17A in axial spondyloarthritis and psoriatic arthritis: Recent advances and controversies. Ann Rheum Dis 78: 1167-1178, 2019.

51. Brown MA, Li Z and Cao KL: Biomarker development for axial spondyloarthritis. Nat Rev Rheumatol 16: 448-463, 2020.

52. Pedersen SJ and Maksymowych WP: The pathogenesis of ankylosing spondylitis: An update. Curr Rheumatol Rep 21: 58, 2019.

53. Kiltz U and Braun J: Current treatment of axial spondylarthritis: Clinical efficacy. Z Rheumatol 79: 13-22, 2020 (In German).

54. Globus RK and Morey-Holton E: Hindlimb unloading: Rodent analog for microgravity. J Appl Physiol (1985) 120: 1196-1206, 2016.

55. Hu Y, Zhang Y, Ni CY, Chen CY, Rao SS, Yin H, Huang J, Tan YJ, Wang ZX, Cao J, et al: Human umbilical cord mesenchymal stromal cells-derived extracellular vesicles exert potent bone protective effects by CLEC11A-mediated regulation of bone metabolism. Theranostics 10: 2293-2308, 2020.

56. Heiland GR, Appel H, Poddubnyy D, Zwerina J, Hueber A, Haibel H, Baraliakos X, Listing J, Rudwaleit M, Schett G and Sieper J: High level of functional dickkopf-1 predicts protection from syndesmophyte formation in patients with ankylosing spondylitis. Ann Rheum Dis 71: 572-574, 2012.

57. Robinson JA, Chatterjee-Kishore M, Yaworsky PJ, Cullen DM, Zhao W, Li C, Kharode Y, Sauter L, Babij P, Brown EL, et al: Wnt/beta-catenin signaling is a normal physiological response to mechanical loading in bone. J Biol Chem 281: 31720-31728, 2006.

58. Uderhardt S, Diarra D, Katzenbeisser J, David JP, Zwerina J, Richards W, Kronke G and Schett G: Blockade of dickkopf (DKK)-1 induces fusion of sacroiliac joints. Ann Rheum Dis 69: 592-597, 2010

59. Xiong JH, Liu J and Chen J: Clinical significance and prognostic value of tumor necrosis factor- $\alpha$ and dickkopf related protein-1 in ankylosing spondylitis. World J Clin Cases 8: 1213-1222, 2020.

60. He C, Li D, Gao J, Li J, Liu Z and Xu W: Inhibition of CXCR4 inhibits the proliferation and osteogenic potential of fibroblasts from ankylosing spondylitis via the Wnt/ $\beta$-catenin pathway. Mol Med Rep 19: 3237-3246, 2019.

61. Blomme B, Deroanne C, Hulin A, Lambert C, Defraigne JO, Nusgens B, Radermecker M and Colige A: Mechanical strain induces a pro-fibrotic phenotype in human mitral valvular interstitial cells through RhoC/ROCK/MRTF-A and Erk1/2 signaling pathways. J Mol Cell Cardiol 135: 149-159, 2019.

62. Hamamura K, Swarnkar G, Tanjung N, Cho E, Li J, Na S and Yokota H: RhoA-mediated signaling in mechanotransduction of osteoblasts. Connect Tissue Res 53: 398-406, 2012

63. Ding Q, Xia W, Liu JC, Yang JY, Lee DF, Xia J, Bartholomeusz G, Li Y,Pan Y,Li Z, et al: Erk associates with and primes GSK-3beta for its inactivation resulting in upregulation of beta-catenin. Mol Cell 19: 159-170, 2005.

64. Abdollah V, Parent EC, Su A, Wachowicz K and Battie MC: Could compression and traction loading improve the ability of magnetic resonance imaging to identify findings related to low back pain? Musculoskelet Sci Pract 50: 102250, 2020.

This work is licensed under a Creative Commons Attribution-NonCommercial-NoDerivatives 4.0 International (CC BY-NC-ND 4.0) License. 